\title{
Hyperinflation on Chest Radiograph as a Marker of Low Adherence to Positive Airway Pressure Therapy in the Overlap Syndrome
}

\author{
Theerakorn Theerakittikul MD, Umur Hatipoğlu MD, and Loutfi S Aboussouan MD
}

\begin{abstract}
BACKGROUND: Positive airway pressure (PAP) in subjects with both obstructive sleep apnea and COPD reduces the risk of pulmonary hypertension, death, and hospitalizations from COPD exacerbations, but adherence to the intervention is low, similar to the experience with noninvasive ventilation in stable COPD. We sought to assess whether hyperinflation on chest radiographs contributes to low adherence to PAP therapy in the overlap syndrome. METHODS: Records of patients with a listed diagnosis of COPD at the time of polysomnography were reviewed. Overlap syndrome was diagnosed when COPD was clinically confirmed with spirometry showing a fixed airway obstruction and when the apnea-hypopnea index was $\geq 5$. Hyperinflation was evaluated by a review of the right diaphragm height on a lateral chest radiograph. Adherence was assessed clinically or through device download at a 3-month follow-up, and later adherence was assessed by telephone interviews. A receiver operating curve was used to determine whether diaphragm height was associated with adherence. RESULTS: Twenty-one of 41 subjects $(51 \%)$ were considered adherent to PAP therapy at the 3-month visit. Adherent subjects were more overweight compared with non-adherent subjects (body mass index of $36.0 \pm 5.7 \mathrm{vs} 32.0 \pm 5.7 \mathrm{~kg} / \mathrm{m}^{2}, P=.03$ ), sleepier at the onset (Epworth sleepiness scale score of $13.0 \pm 5.8$ vs $9.4 \pm 5.4, P<.05$ ), and less likely to have hyperinflation as defined by a right diaphragm height $\leq 2.45 \mathrm{~cm}(33 \%$ vs $65 \%, P=.04)$. The body mass index and initial sleepiness no longer predicted adherence beyond 3 months, but $35 \%$ of subjects with a right diaphragm height $\leq \mathbf{2 . 4 5} \mathrm{cm}$ were adherent beyond 3 months compared with $75 \%$ of those with a right diaphragm height $>2.45 \mathrm{~cm}(P=.04$ by Fisher exact test $)$. CONCLUSIONS: Hyperinflation is associated with decreased adherence to PAP therapy in the overlap syndrome. Key words: obstructive sleep apnea; chronic obstructive pulmonary disease; airway obstruction; continuous positive airway pressure; patient compliance; positive-pressure respiration. [Respir Care 2014;59(8):1267-1274. ( 2014 Daedalus Enterprises]
\end{abstract}

\section{Introduction}

The overlap syndrome, representing a combination of obstructive sleep apnea-hypopnea syndrome and COPD, is

\footnotetext{
Dr Theerakittikul is affiliated with the Pulmonary Critical Care and Allergy Unit, Department of Internal Medicine, Faculty of Medicine, Chiang Mai University, Chiang Mai, Thailand. Drs Hatipoğlu and Aboussouan are affiliated with the Department of Pulmonary, Allergy, and Critical Care Medicine, Respiratory Institute, and Dr Aboussouan is also affiliated with the Sleep Disorders Center, Neurological Institute, Cleveland Clinic, Cleveland, Ohio.
}

Dr Aboussouan received royalties from UpToDate. Dr Hatipoğlu received a grant from Novartis and honoraria for speaking engagements from Forest Laboratories. Dr Theerakittikul has disclosed no conflicts of interest. associated with an increased risk of pulmonary hypertension, right heart failure, death, and hospitalization from COPD exacerbations. ${ }^{1-3}$ Although positive airway pressure (PAP) treatment improves survival and decreases hospitalizations in this group of patients, acceptance of the intervention device is low, with $46 \%$ of subjects refusing to use PAP in one study. ${ }^{3}$ This experience is similar to the low adherence (37-57\%) to noninvasive ventilation (NIV)

\footnotetext{
Correspondence: Loutfi S Aboussouan MD, Sleep Disorders Center, Neurological Institute, and Department of Pulmonary, Allergy, and Critical Care Medicine, Respiratory Institute, Cleveland Clinic, A-90, 9500 Euclid Avenue, Cleveland, OH 44195. E-mail: aboussl@ccf.org.
}

DOI: $10.4187 /$ respcare.03011 
in subjects with stable COPD. ${ }^{4-6}$ Therefore, the identification and remediation of factors that decrease adherence are necessary to extend the benefits of PAP therapy to patients with the overlap syndrome or with stable COPD.

One potential explanation for the decreased adherence to NIV in COPD with or without obstructive sleep apnea may be an increase in end-expiratory lung volume as a consequence of PAP. ${ }^{7}$ Although this effect may be beneficial in restrictive and neuromuscular disorders, it may contribute to intolerance in subjects with COPD, particularly those with hyperinflation at baseline. For instance, hyperinflation limits the ability of the diaphragm to increase lung volume ${ }^{8}$ and can further increase the oxygen cost of breathing during resistive breathing. ${ }^{9}$

These considerations are of particular relevance in the overlap syndrome, in which PAP, as indicated for sleep apnea, may be met with the same adherence issues as with NIV in COPD. Accordingly, patients with the overlap syndrome provide a unique opportunity to assess determinants of adherence to PAP therapy in COPD. In this study, we specifically sought to determine whether hyperinflation, as measured by the position of the diaphragm on a lateral chest radiograph, is a marker of low adherence to PAP therapy in the overlap syndrome.

\section{Methods}

\section{Subject Selection}

This study was approved by the investigational review board of the Cleveland Clinic. We reviewed records of adults ( $\geq 18 \mathrm{y}$ ) referred for a full-night attended polysomnography from January 2005 to December 2009. Pregnant women were excluded. The polysomnographic records included a searchable database of patient-reported and technician-entered medical diagnoses with the search targeted at the terms chronic airway obstruction, chronic obstructive pulmonary disease, COPD, and emphysema. Demographics were collected, and subjects were considered to have the overlap syndrome when they had both COPD and obstructive sleep apnea. The diagnosis of COPD was confirmed by review of the medical records for a clinical diagnosis of COPD along with spirometric data meeting the diagnostic criteria of the Global Initiative for Chronic Obstructive Lung Disease with a post-bronchodilator $\mathrm{FEV}_{1} / \mathrm{FVC}$ of $<0.70 .{ }^{10}$ The obstructive sleep apnea-hypopnea syndrome was as defined by the American Academy of Sleep Medicine, with an apnea-hypopnea index of $\geq 5$ along with signs or symptoms of disturbed sleep. ${ }^{11} \mathrm{~A}$ flow diagram of the final subject selection is show in Figure 1.

\section{QUICK LOOK}

\section{Current knowledge}

Positive airway pressure (PAP) in patients with both obstructive sleep apnea and COPD reduces the risk of pulmonary hypertension, death, and hospitalizations from exacerbations. Adherence to PAP therapy is poor despite the known salutary effects.

\section{What this paper contributes to our knowledge}

A retrospective review of subjects with both sleep apnea and COPD suggests that hyperinflation, as assessed by the right diaphragm position on a lateral radiograph, adversely affects adherence to PAP therapy. In these subjects, increased hyperinflation may increase non-adherence.

\section{Measures}

Pulmonary function tests were performed with MasterScreen PFT systems (Erich Jaeger, Friedberg, Germany). The spirometric studies followed the specifications of the American Thoracic Society/European Respiratory Society. Predicted variables used the Third National Health and Nutrition Examination Survey reference. ${ }^{12}$ Diffusion capacity was also collected when available.

All sleep studies were full-night attended laboratory polysomnographies, manually scored by technicians and then reviewed by board-certified sleep medicine physicians using the 2007 scoring rules of the American Academy of Sleep Medicine. ${ }^{13}$

Polysomnographic variables were collected, as well as the type of PAP (CPAP vs bi-level PAP [BPAP]) and the optimum pressure level achieved during the PAP titration. Optimum PAP was defined as the pressure value (CPAP or the inspiratory pressure for a BPAP device) that abolished all respiratory events, arousals, and desaturation episodes.

The chest roentgenograms were independently reviewed without information from the polysomnography or medical records. The electronic ruler in the viewers' applications (Syngo and MagicWeb Image Viewer programs, Siemens, Berlin, Germany) was used to measure the right diaphragmatic arc on the lateral film. These systems conform to the quantitative criteria of the American Association of Physicists in Medicine with a spatial accuracy within $2 \% .{ }^{14}$ Left lateral radiographs were obtained with the left chest against the film cassette and with a sourceimage distance of at least $180 \mathrm{~cm}$ to minimize beam divergence. ${ }^{14}$ The technique of Reich et $\mathrm{al}^{15}$ was used with measurement of a line normal to the right diaphragmatic 


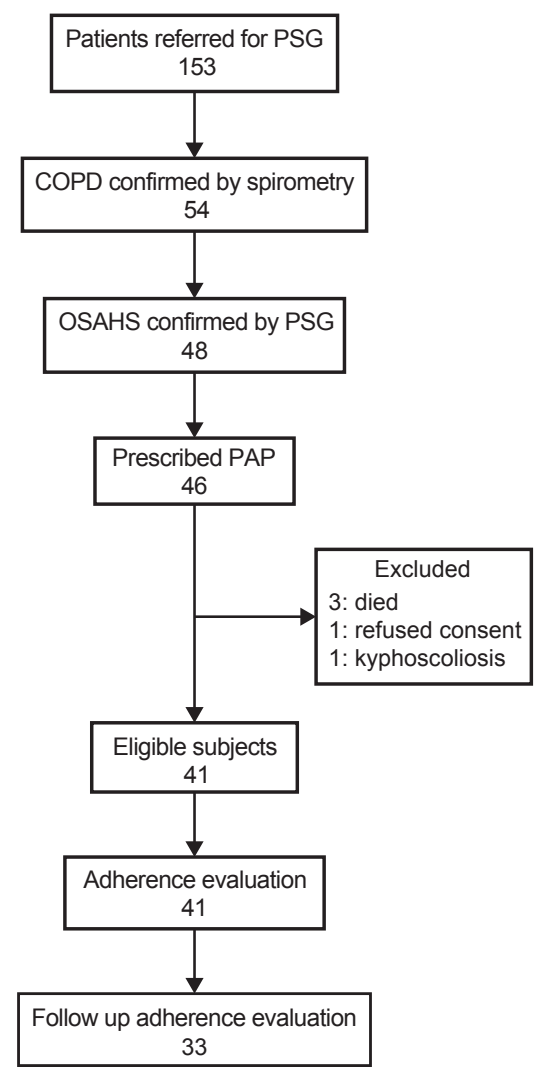

Fig. 1. Study flow chart. PSG = polysomnography; OSAHS = obstructive sleep apnea-hypopnea syndrome; PAP = positive airway pressure.

curve at its apex and normal to a line drawn between the posterior and anterior costophrenic angles (Fig. 2).

An initial assessment was made at 3 months from initiation of PAP. Later tolerance was assessed beyond 3 months when available. For the initial assessment visit, adherence was based on a device download when available or on review of chart records for self-reported device use. The assessment of adherence beyond 3 months was based on review of records and direct interview of the subject by telephone if records did not include the required information. The specific information sought in medical record reviews and telephone interviews included how long the subjects used the device on average (in $\mathrm{h} / \mathrm{d}$ ) and how often they used it on average (in $\mathrm{d} /$ week). The specific information sought on device download included the average usage in hours (on days used) and the percentage of days with usage $\geq 4 \mathrm{~h}$. For chart review and telephone interviews, adherence was defined as use of the PAP device for $\geq 4 \mathrm{~h} /$ night for at least 5 nights/week. For device download, adherence was defined as an average use of the PAP device of $\geq 4 \mathrm{~h} / \mathrm{night}$ on days used for at least $70 \%$ of the nights.

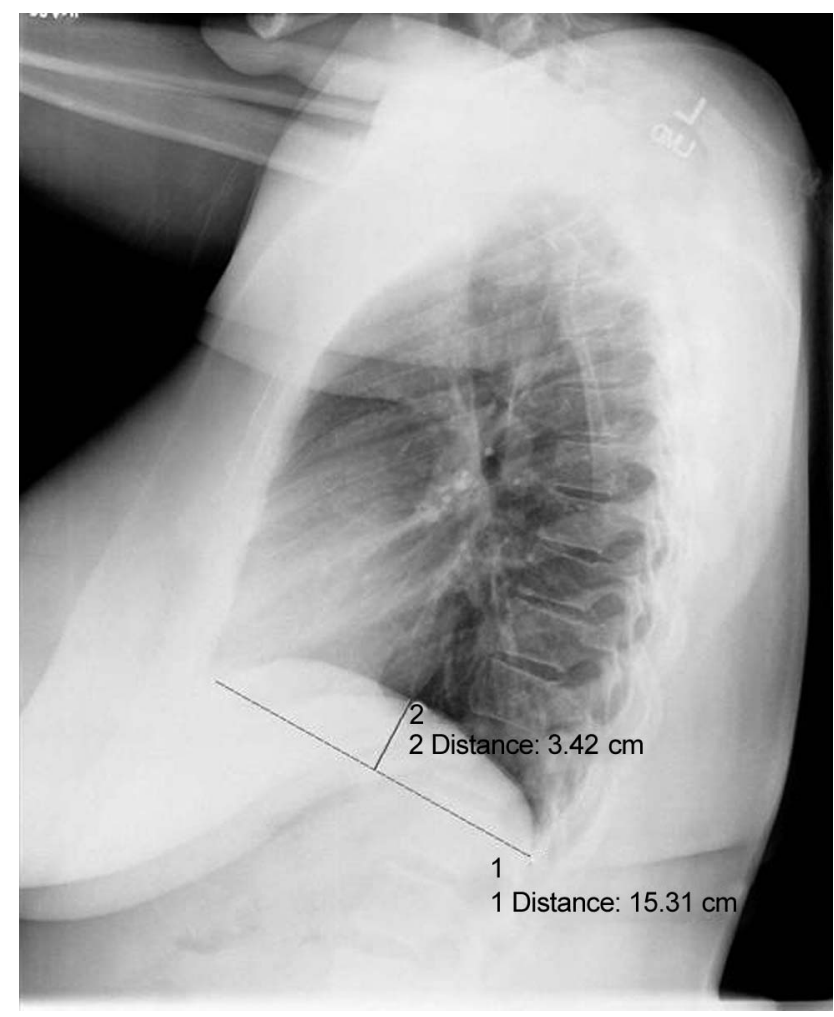

Fig. 2. The right diaphragmatic arc height was the measurement of a line normal to the right diaphragmatic curve at its apex and normal to a line drawn between the posterior and anterior costophrenic angles.

\section{Statistical Analysis}

All variables were assessed for normality using the Shapiro-Wilk test. Continuous variables were presented as mean $\pm \mathrm{SD}$. Comparison of variables between groups was performed by $t$ tests or the Mann-Whitney $U$ test depending on the data distribution. Two-by-two cross-tabulation analyses were performed using the Fisher exact test or chi-square test. Receiver operating characteristic (ROC) plots were obtained, and area under the ROC curve analysis was performed to assess the predictive value of diaphragm height for adherence to PAP therapy. The ROC table and curves were then reviewed to identify a cutoff with the best sensitivity and specificity. Significance was defined as $P<.05$. All analyses were done with SPSS 11.5 (SPSS, Chicago, Illinois).

\section{Results}

A diagnosis of chronic airway obstruction, COPD, or emphysema was found in 153 subjects. Of those, 54 were confirmed as having COPD based on both a chart review and an existing spirometry showing a post-bronchodilator $\mathrm{FEV}_{1} / \mathrm{FVC}$ of $<0.70$. The overlap syndrome (ie, concur- 
RAdiographic Hyperinflation and Decreased PAP AdHerence in the Overlap Syndrome

Table 1. Demographic, Polysomnographic, and Pulmonary Function Characteristics Separated by Positive Airway Pressure Adherence at 3 Months

\begin{tabular}{|c|c|c|c|c|}
\hline Variable & Overall Group $(n=41)$ & Non-adherent Group $(n=20)$ & Adherent Group $(n=21)$ & $P$ \\
\hline Age, y & $67.7 \pm 8.8(47-84)$ & $69.0 \pm 8.9$ & $66.5 \pm 8.7$ & .36 \\
\hline Proportion of females (males/females), \% & $41.4(24 / 17)$ & $45(11 / 9)$ & $38.1(13 / 8)$ & $.65^{*}$ \\
\hline BMI, $\mathrm{kg} / \mathrm{m}^{2}$ & $34.1 \pm 6.0(23.7-51.4)$ & $32.0 \pm 5.7$ & $36.0 \pm 5.7$ & .03 \\
\hline Epworth sleepiness scale & $11.2 \pm 5.9(0-22)$ & $9.4 \pm 5.4$ & $13.0 \pm 5.8$ & .05 \\
\hline AHI, events/h & $36.8 \pm 26.1(6.3-94.9)$ & $37.9 \pm 24.7$ & $35.6 \pm 28.1$ & $.48 \dagger$ \\
\hline REM sleep, \% & $14.2 \pm 8.6(0-47.5)$ & $11.6 \pm 6.7$ & $16.9 \pm 9.6$ & $.09 \dagger$ \\
\hline Non-REM sleep, $\%$ & $84.0 \pm 13.9(16-100)$ & $88.4 \pm 6.7$ & $79.9 \pm 17.5$ & $.06 \dagger$ \\
\hline Sleep latency, min & $27.7 \pm 24.3(1-114)$ & $32.1 \pm 29.7$ & $23.5 \pm 17.4$ & $.60 \dagger$ \\
\hline Sleep efficiency, $\%$ & $68.6 \pm 17.0(28-98)$ & $65.6 \pm 18.3$ & $71.4 \pm 15.5$ & .28 \\
\hline Total sleep time $<90 \%, \%$ & $36.1 \pm 32.7(0-95)$ & $44.0 \pm 32.7$ & $27.9 \pm 31.5$ & $.06 \dagger$ \\
\hline $\mathrm{FEV}_{1}, \%$ predicted & $58.5 \pm 17.4(25-106)$ & $61 \pm 20$ & $56 \pm 15$ & .31 \\
\hline $\mathrm{FEV}_{1} / \mathrm{FVC}$ & $0.56 \pm 0.11(26-69)$ & $0.54 \pm 0.12$ & $0.60 \pm 0.10$ & .45 \\
\hline $\mathrm{D}_{\mathrm{LCO}}, \%$ predicted & $60 \pm 19(30-98)$ & $59 \pm 19(n=17)$ & $62 \pm 19(n=13)$ & .60 \\
\hline $\begin{array}{l}\text { Values are means } \pm \text { SD (range) } \\
* \text { Pearson chi-square text } \\
\dagger \text { Mann-Whitney } U \text { test } \\
\text { BMI = body mass index } \\
\text { AHI }=\text { apnea-hypopnea index } \\
\text { REM = rapid eye movement } \\
D_{\text {LCO }}=\text { diffusing capacity of the lung for carbon monoxide }\end{array}$ & & & & \\
\hline
\end{tabular}

rent obstructive sleep apnea-hypopnea syndrome) was found in 48 of those subjects. Positive airway therapy was prescribed for 46 of those subjects. Three subjects died before completing the compliance evaluation, and one subject declined to have a follow-up for a CPAP adherence evaluation. Another subject was excluded because his chest radiograph showed severe kyphoscoliosis (see Fig. 1).

The remaining 41 subjects were included in this cohort. Chest roentgenograms were available for all 24 male and 17 female subjects. This group tended to be older (mean age of $68 \mathrm{y}$ ) and overweight (mean body mass index of 34 $\mathrm{kg} / \mathrm{m}^{2}$ ) and to have severe sleep apnea (mean apnea-hypopnea index of 37 events/h) and moderate COPD (mean $\mathrm{FEV}_{1}$ 59\%) (Table 1).

At the 3-month evaluation, adherence from a device download was available in 6 subjects, and the remaining adherence information was obtained from records. Twenty subjects were considered non-adherent to PAP therapy, and 21 were considered adherent (51\% adherence). The baseline demographic, polysomnographic, and pulmonary function characteristics separated by adherence status at 3 months are shown in Table 1. Baseline characteristics associated with improved adherence included a higher weight and higher degree of sleepiness at the time of the initial polysomnography. There was no significant difference between the adherent and non-adherent groups in the apnea-hypopnea index or in COPD severity as assessed by the percent-of-predicted $\mathrm{FEV}_{1}$ or $\mathrm{FEV}_{1} / \mathrm{FVC}$. Diffusion capacity was available for 30 subjects (17 non-adherent and 13 adherent) and was not significantly different between the 2 groups (non-adherent: $59 \pm 19 \%$, adherent:
$62 \pm 19 \%, P=.60)$. The modality of positive airway therapy and the pressure prescribed did not predict adherence. Specifically, 18 of 35 subjects on a CPAP mode $(51.4 \%)$ were adherent compared with 3 of 6 subjects $(50 \%)$ on a BPAP mode ( $P=.65$ by Fisher exact test). BPAP was recommended in those 6 subjects because of intolerance of CPAP (4 subjects) or poor control of sleep apnea at $\mathrm{CPAP} \geq 15 \mathrm{~cm} \mathrm{H}_{2} \mathrm{O}$ (2 subjects). The optimum pressure (CPAP or inspiratory PAP) was also similar between non-adherent and adherent groups (11.35 $\pm 3.0 \mathrm{vs}$ $12.19 \pm 3.0 \mathrm{~cm} \mathrm{H}_{2} \mathrm{O}, P=.44$ by Mann-Whitney $U$ test).

The right diaphragmatic arc was significantly higher with adherence such that the median (interquartile range) was $2.82(2.02-3.71) \mathrm{cm}$ for adherent subjects compared with $2.07(1.69-3.08) \mathrm{cm}$ for non-adherent subjects ( $P=.04$ by Mann-Whitney $U$ test). Similarly, an ROC curve indicated that diaphragm height on the lateral view was predictive of adherence at 3 months, with an area under the curve of $0.69(P=.04)$ (Fig. 3). A review of the coordinates of this curve indicated the best sensitivity and specificity to predict adherence at a diaphragm height cutoff of $2.45 \mathrm{~cm}$. The sensitivity and specificity of the right diaphragmatic arc at a cutoff of $2.45 \mathrm{~cm}$ for adherence were $65 \%$ and $67 \%$, respectively. As a corollary, only $35 \%$ of subjects with a flatter diaphragm (right diaphragmatic arc $\leq 2.45 \mathrm{~cm}$ ) were adherent to PAP at 3 months compared with $67 \%$ of those with a more curved diaphragm (right diaphragmatic arc $>2.45 \mathrm{~cm})(P=.04$ by chisquare test).

Compared with subjects with a flatter diaphragm, those with a more curved diaphragm were also more overweight 


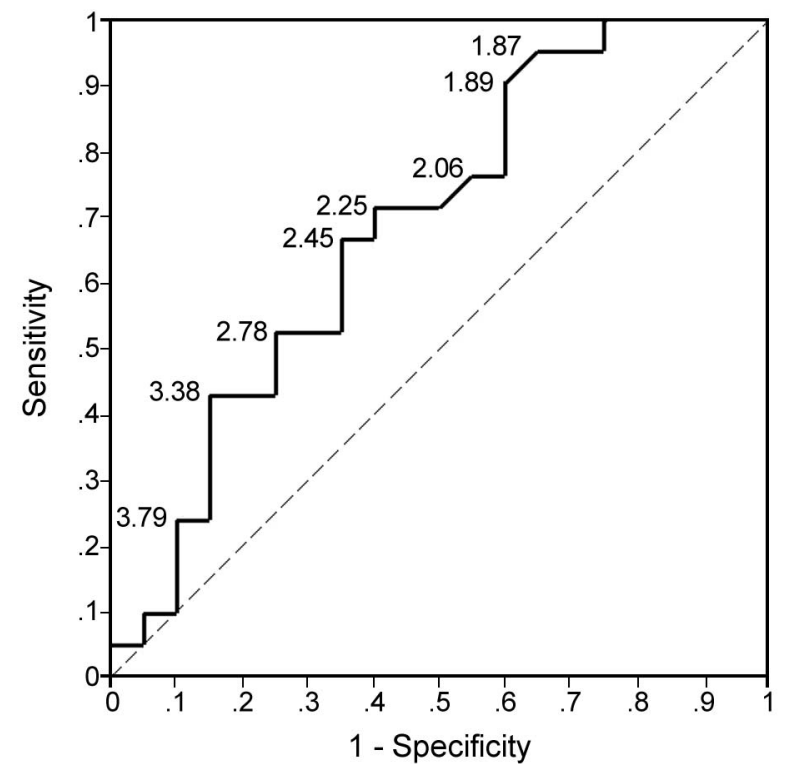

Fig. 3. Receiver operating characteristic curve for right diaphragmatic arc height in the assessment of adherence to positive airway pressure therapy at 3 months. The curve describes the sensitivity and specificity at different cutoffs of the right diaphragmatic arc. The height in centimeters corresponding to selected coordinates is shown. The cutoff value of $2.45 \mathrm{~cm}$ in the text was the value with the highest sensitivity and specificity.

(body mass index of $36.2 \pm 6.6$ vs $31.8 \pm 4.3 \mathrm{~kg} / \mathrm{m}^{2}$, $P=.02)$, had more rapid eye movement sleep $(18.3 \pm 9.1 \%$ vs $10.2 \pm 5.8 \%, P<.01$ by Mann-Whitney $U$ test) and a lower apnea-hypopnea index ( $31.3 \pm 28.0$ vs $42.4 \pm 23.2$ events/h, $P=.04$ by Mann-Whitney $U$ test), and trended toward a higher diffusion capacity $(67.6 \pm 18.1 \%$ vs $54.8 \pm 17.6 \%, P=.06$ ). Lung volumes were available in only 19 subjects (46\%), with a clear bias toward availability of lung volumes in subjects with a flatter diaphragm. For instance, lung volumes were available in $70 \%$ of subjects (14/20) with a flatter diaphragm compared with only $23 \%$ of subjects $(5 / 21)$ with a more curved diaphragm $(P<.01$ by Fisher exact test $)$.

Later adherence (beyond 3 months) was available for 33 subjects. The right diaphragmatic arc was associated with later adherence, with an ROC curve showing an area under the curve of $0.74(P=.02)$. The same cutoff of $2.45 \mathrm{~cm}$ had the best sensitivity and specificity for predicting late adherence. Specifically, only 6 of 17 subjects (35\%) with a flatter diaphragm (right diaphragmatic arc $\leq 2.45 \mathrm{~cm}$ ) were adherent to PAP beyond 3 months compared with 12 of 16 subjects (75\%) with a more curved diaphragm (right diaphragmatic arc $>2.45 \mathrm{~cm})(P=.04$ by Fisher exact test). Heavier weight was no longer predictive of later tolerance, but later adherent subjects tended to have a higher diffusion capacity (Table 2). In general, adherence at 3 months predicted later adherence: $88 \%$ of subjects $(15 / 17)$ who were adherent at 3 months were also adherent
Table 2. Demographic, Polysomnographic, and Pulmonary Function Characteristics Separated by Positive Airway Pressure Adherence Beyond 3 Months

\begin{tabular}{|c|c|c|c|}
\hline Variable & $\begin{array}{c}\text { Non-adherent } \\
\text { Group } \\
(n=15)\end{array}$ & $\begin{array}{c}\text { Adherent } \\
\text { Group } \\
(n=18)\end{array}$ & $P$ \\
\hline Age, y & $70.2 \pm 8.9$ & $66.7 \pm 9.4$ & .29 \\
\hline $\begin{array}{l}\text { Proportion of females } \\
\text { (males/females), } \%\end{array}$ & $53(7 / 8)$ & $33(12 / 6)$ & $.25^{*}$ \\
\hline BMI, $\mathrm{kg} / \mathrm{m}^{2}$ & $32.6 \pm 5.2$ & $34.1 \pm 6.2$ & .48 \\
\hline Epworth sleepiness scale & $8.7 \pm 5.9$ & $12.4 \pm 5.3$ & .07 \\
\hline AHI, events/h & $40.0 \pm 26.6$ & $30.7 \pm 24.5$ & $.15 \dagger$ \\
\hline REM, \% & $11.3 \pm 6.6$ & $14.9 \pm 9.8$ & $.21 \dagger$ \\
\hline Non-REM, \% & $88.7 \pm 6.6$ & $81.3 \pm 19.1$ & $.18 \dagger$ \\
\hline Sleep latency, min & $30.8 \pm 31.1$ & $22.3 \pm 16.2$ & $.79 \dagger$ \\
\hline Sleep efficiency, $\%$ & $59.0 \pm 20.5$ & $73.7 \pm 9.5$ & .01 \\
\hline Total sleep time $<90 \%, \%$ & $48.2 \pm 36.2$ & $27.8 \pm 31.8$ & $.07 \dagger$ \\
\hline $\mathrm{FEV}_{1}, \%$ predicted & $59 \pm 20$ & $60 \pm 15$ & .31 \\
\hline $\mathrm{FEV}_{1} / \mathrm{FVC}$ & $0.54 \pm 0.12$ & $0.60 \pm 0.10$ & .86 \\
\hline $\mathrm{D}_{\mathrm{LCO}}, \%$ predicted & $53 \pm 17(n=12)$ & $69 \pm 21(n=12)$ & .06 \\
\hline
\end{tabular}

$\overline{\text { Values are means } \pm S D}$

* Pearson chi-square text

$\dagger$ Mann-Whitney $U$ test

$\mathrm{BMI}=$ body mass index

$\mathrm{AHI}=$ apnea-hypopnea index

$\mathrm{REM}=$ rapid eye movement

$\mathrm{D}_{\mathrm{LCO}}=$ diffusing capacity of the lung for carbon monoxide

at a later time point, and $81 \%$ of subjects (13/16) who were non-adherent at 3 months were also non-adherent at a later time point. Of the 3 non-adherent subjects who became adherent, 2 had a flat diaphragm $(\leq 2.45 \mathrm{~cm})$, and both initially adherent subjects who became non-adherent also had a flat diaphragm.

\section{Discussion}

In this study of subjects with well-defined overlap syndrome, we found that hyperinflation, as assessed by the diaphragm position on a lateral view, is associated with reduced nocturnal adherence to PAP therapy. Specifically, the proportion of nocturnal adherence to PAP therapy in subjects with a more elevated (curved) diaphragm was twice that in subjects with a lower (flat) diaphragm (67\% vs $35 \%$ for early adherence and $75 \%$ vs $35 \%$ for later adherence). We additionally confirmed results of other studies showing that increased body weight ${ }^{16-19}$ and more symptomatic severity of sleep apnea as assessed by sleepiness ${ }^{20,21}$ predict better early adherence. We did not find an association between the apnea-hypopnea index and adherence, consistent with studies showing a weak-to-absent association with the apnea-hypopnea index.22

Increased severity of hyperinflation in COPD is associated with worse sleep efficiency, even after adjustment for confounders such as body mass index, apnea-hypopnea 
index, $\mathrm{FEV}_{1}$, or extent of nocturnal hypoxemia. ${ }^{23}$ The implications of our findings for positive airway therapy in COPD are significant since hyperinflation and consequent reduced adherence to PAP therapy may compound these issues. Some studies suggest that more judicious use of PAP therapy may be part of the solution. For instance, NIV reduces total lung capacity by $10 \%$ in stable hypercapnic COPD, possibly from increased cross-sectional areas of the airways, decreased airway resistance, and increased expiratory time, which may facilitate the emptying of diseased lung units. 24,25 In contrast, other studies have shown that CPAP only temporarily decreases hyperinflation in COPD. ${ }^{26}$ Similarly, high-resolution computed tomographic studies show that although low CPAP $\left(5 \mathrm{~cm} \mathrm{H}_{2} \mathrm{O}\right.$ ) may cause regional deflation in some subjects, higher CPAP $\left(10-15 \mathrm{~cm} \mathrm{H}_{2} \mathrm{O}\right)$ may promote overinflation of already hyperinflated zones. ${ }^{25}$ One study showed that generally low CPAP $\left(4-11 \mathrm{~cm} \mathrm{H}_{2} \mathrm{O}\right)$ in COPD can be individualized to the level best associated with an improvement in inspiratory capacity particularly in subjects with an emphysema phenotype rather than a chronic bronchitis phenotype of COPD. ${ }^{27}$ Although we did not classify our subjects based on the COPD phenotype, our study does suggest that subjects with increased weight (more commonly associated with the chronic bronchitis phenotype) have better adherence (see Table 1), whereas those with lower diffusion capacity (more commonly associated with the emphysema phenotype) have a flatter diaphragm and reduced later adherence (see Table 2). Finally, in a landmark physiologic study performed in mechanically ventilated subjects, application of extrinsic PEEP in excess of intrinsic PEEP increased end-expiratory total gas volume. ${ }^{28}$ Therefore, a critical value for externally applied pressure may exist after which hyperinflation occurs, particularly in subjects with expiratory flow obstruction.

Taken together, these studies favor a strategy of a lower PAP in subjects with COPD, with the additional challenge that the selected pressure should also control the obstructive sleep apnea in the overlap syndrome. Although we were unable to show a difference in the optimum pressure delivered when comparing adherent and non-adherent subjects, our study suggests that such a lower PAP strategy may best be targeted to individuals with hyperinflation, thereby lowering the threshold for options such as positional therapy or auto-titrating PAP therapy, which can reduce overall pressure and promote adherence in the overlap syndrome, as has been shown in subjects with obstructive sleep apnea-hypopnea syndrome who require higher CPAP. ${ }^{29}$

The low adherence to PAP therapy in patients with the overlap syndrome is similar to the experience with NIV in subjects with stable COPD. ${ }^{4-6}$ This disappointing experience stands in sharp contrast to that with NIV in COPD exacerbations, where it is considered a standard of care, ${ }^{30}$ and that in subjects with more severe hypercapnic COPD, where NIV with higher airway pressures is generally better tolerated ${ }^{31}$ and can be associated with a survival advantage. ${ }^{5}$ The difference may be that in severe COPD, PAP can compensate for the threshold load imposed by intrinsic PEEP, ${ }^{32}$ decrease the intrinsic PEEP, ${ }^{7}$ and relieve the respiratory muscle fatigue and weakness imposed by the mechanically disadvantageous diaphragm configuration imposed by hyperinflation. ${ }^{8}$

In contrast, intrinsic PEEP may or may not be significantly increased in stable COPD, with studies indicating a mean intrinsic PEEP of $<3 \mathrm{~cm} \mathrm{H}_{2} \mathrm{O}$ in stable but severe COPD. ${ }^{7}$ Furthermore, any reduction of intrinsic PEEP with COPD results in a marginal deflating effect, and the reductions in effort of breathing may occur at the expense of increases in end-expiratory lung volume, which may aggravate the hyperinflation, ${ }^{7}$ which in turn limits the ability of the diaphragm to increase lung volume ${ }^{8}$ and increases oxygen cost of breathing during resistive breathing. ${ }^{9}$

It is noteworthy that our best cutoff of $2.45 \mathrm{~cm}$ is close to the 2.6-cm cutoff of Reich et al, ${ }^{15}$ who found that a right diaphragmatic arc height of $\leq 2.6 \mathrm{~cm}$ identified $68 \%$ of subjects with abnormal pulmonary function tests, suggesting COPD. Although other radiographic parameters such as lung length and retrosternal lucency are also correlated with a COPD diagnosis, we chose the height of the right diaphragmatic arc based on the results of Reich et al, 15 the greater dependence of other parameters (such as lung length) on the subject's morphometry (such as height), and studies showing diaphragm flattening as having a better correlation with postmortem changes in emphysema. ${ }^{33}$ For instance, in our study, an ROC analysis showed that the lung length (distance from the tubercle of the first rib to the top of the dome of the right diaphragm on a posteriorto-anterior chest projection) did not predict adherence (area under the curve of $0.49, P=.91$ ) and that lung length significantly correlated with the subject's height $(\mathrm{r}=0.46$, $P<.01)$.

Although the sample size was small, we were able to document the deleterious aspect of hyperinflation because of a large effect size with a doubling of adherence in subjects with a curved diaphragm compared with a flat diaphragm. Also, the small area under the ROC curve in our study fully answers our question of whether hyperinflation is associated with low adherence. A higher area under the curve would have been required for a diagnostic test in which accuracy is important but cannot be expected in this context, given the complexity of factors (interface, subjects' characteristics, severity of sleep apnea, psychosocial, etc) associated with PAP adherence. ${ }^{34}$

A limitation of our study is that fewer than half our subjects had lung volume studies, reducing our ability to compare adherence by physiologic rather than anatomic markers of hyperinflation or air trapping. This may reflect 
the lesser importance of lung volumes in the assessment of obstructive relative to restrictive lung diseases. We were not able to show any significant difference in lung volumes between adherent and non-adherent groups or between subjects with flat or curved diaphragms. However, that comparison was limited by a clear bias toward obtaining lung volume studies in subjects with more anatomic hyperinflation such that only 5 subjects with a curved diaphragm had lung volume studies.

A more significant limitation of our study is that adherence was partially determined by subject interviews. This limitation would have the effect of overestimating the subjects considered to be adherent to therapy, as objective CPAP adherence is generally overestimated by $>60 \mathrm{~min}, 35$ but cannot be expected to bias toward our findings of improved adherence in subjects who were overweight or severely sleepy or who had a more elevated diaphragm position.

Future studies could address this limitation given the more widespread use of adherence monitoring, assess the impact of physiologically as well as radiographically determined hyperinflation, and evaluate the effect of a lower PAP strategy on adherence in the overlap syndrome.

In conclusion, our findings indicate that hyperinflation, as assessed by the right diaphragm position on a lateral radiograph, may adversely affect adherence to PAP therapy in subjects with the overlap syndrome. Since hyperinflation in COPD is associated with worse sleep efficiency, ${ }^{23}$ increased non-adherence to treatment in the presence of hyperinflation may negatively impact the care of these particularly vulnerable subjects. This finding may have direct implications, such as possible selection of lower pressures in overlap syndrome subjects with hyperinflation.

\section{REFERENCES}

1. Bradley TD, Rutherford R, Grossman RF, Lue F, Zamel N, Moldofsky H, Phillipson EA. Role of daytime hypoxemia in the pathogenesis of right heart failure in the obstructive sleep apnea syndrome. Am Rev Respir Dis 1985;131(6):835-839.

2. Chaouat A, Weitzenblum E, Krieger J, Ifoundza T, Oswald M, Kessler R. Association of chronic obstructive pulmonary disease and sleep apnea syndrome. Am J Respir Crit Care Med 1995;151(1):8286.

3. Marin JM, Soriano JB, Carrizo SJ, Boldova A, Celli BR. Outcomes in patients with chronic obstructive pulmonary disease and obstructive sleep apnea: the overlap syndrome. Am J Respir Crit Care Med 2010;182(3):325-331.

4. Criner GJ, Brennan K, Travaline JM, Kreimer D. Efficacy and compliance with noninvasive positive pressure ventilation in patients with chronic respiratory failure. Chest 1999;116(3):667-675.

5. McEvoy RD, Pierce RJ, Hillman D, Esterman A, Ellis EE, Catcheside $\mathrm{PG}$, et al. Nocturnal non-invasive nasal ventilation in stable hypercapnic COPD: a randomised controlled trial. Thorax 2009;64(7): 561-566.

6. Strumpf DA, Millman RP, Carlisle CC, Grattan LM, Ryan SM, Erickson AD, Hill NS. Nocturnal positive-pressure ventilation via nasal mask in patients with severe chronic obstructive pulmonary disease. Am Rev Respir Dis 1991;144(6):1234-1239.

7. O'Donoghue FJ, Catcheside PG, Jordan AS, Bersten AD, McEvoy RD. Effect of CPAP on intrinsic PEEP, inspiratory effort, and lung volume in severe stable COPD. Thorax 2002;57(6):533-539.

8. De Troyer A. Effect of hyperinflation on the diaphragm. Eur Respir J 1997;10(3):708-713.

9. Collett PW, Engel LA. Influence of lung volume on oxygen cost of resistive breathing. J Appl Physiol 1986;61(1):16-24.

10. Vestbo J, Hurd SS, Agustí AG, Jones PW, Vogelmeier C, Anzueto A, et al. Global strategy for the diagnosis, management, and prevention of chronic obstructive pulmonary disease: GOLD Executive Summary. Am J Respir Crit Care Med 2013;187(4):347-365.

11. American Academy of Sleep Medicine. International classification of sleep disorders: diagnostic and coding manual, 2nd edition. Westchester, Illinois: American Academy of Sleep Medicine; 2005.

12. Hankinson JL, Odencrantz JR, Fedan KB. Spirometric reference values from a sample of the general U.S. population. Am J Respir Crit Care Med 1999;159(1):179-187.

13. Iber C, Ancoli-Israel S, Chesson AL, Quan SF. The AASM manual for the scoring of sleep and associated events: rules, terminology and technical specifications. Westchester, Illinois: American Academy of Sleep Medicine; 2007.

14. Report of AAPM Task Group 10. Acceptance testing and quality control of photostimulable storage phosphor imaging systems. Report No. 93, 2006. https://www.aapm.org/pubs/reports/RPT_93.pdf. Accessed June 19, 2014.

15. Reich SB, Weinshelbaum A, Yee J. Correlation of radiographic measurements and pulmonary function tests in chronic obstructive pulmonary disease. AJR 1985;144(4):695-699.

16. Krieger J, Kurtz D, Petiau C, Sforza E, Trautmann D. Long-term compliance with CPAP therapy in obstructive sleep apnea patients and in snorers. Sleep 1996;19(9 Suppl):S136-S143.

17. Edinger JD, Carwile S, Miller P, Hope V, Mayti C. Psychological status, syndromatic measures, and compliance with nasal CPAP therapy for sleep apnea. Percept Mot Skills 1994;78(3 Pt 2):11161118.

18. Nino-Murcia G, McCann CC, Bliwise DL, Guilleminault C, Dement WC. Compliance and side effects in sleep apnea patients treated with nasal continuous positive airway pressure. West J Med 1989;150(2): 165-169.

19. Hoffstein V, Viner S, Mateika S, Conway J. Treatment of obstructive sleep apnea with nasal continuous positive airway pressure. Patient compliance, perception of benefits, and side effects. Am Rev Respir Dis 1992;145(4 Pt 1):841-845.

20. Wolkove N, Baltzan M, Kamel H, Dabrusin R, Palayew M. Longterm compliance with continuous positive airway pressure in patients with obstructive sleep apnea. Can Respir J 2008;15(7):365-369.

21. McArdle N, Devereux G, Heidarnejad H, Engleman HM, Mackay TW, Douglas NJ. Long-term use of CPAP therapy for sleep apnea/ hypopnea syndrome. Am J Respir Crit Care Med 1999;159(4 Pt 1):1108-1114.

22. Weaver TE, Grunstein RR. Adherence to continuous positive airway pressure therapy: the challenge to effective treatment. Proc Am Thorac Soc 2008;5(2):173-178.

23. Kwon JS, Wolfe LF, Lu BS, Kalhan R. Hyperinflation is associated with lower sleep efficiency in COPD with co-existent obstructive sleep apnea. COPD 2009;6(6):441-445.

24. Díaz O, Bégin P, Torrealba B, Jover E, Lisboa C. Effects of noninvasive ventilation on lung hyperinflation in stable hypercapnic COPD. Eur Respir J 2002;20(6):1490-1498.

25. Holanda MA, Fortaleza SC, Alves-de-Almeida M, Winkeler GF, Reis RC, Felix JH, et al. Continuous positive airway pressure effects 


\section{Radiographic Hyperinflation and Decreased PAP AdHerence in the Overlap Syndrome}

on regional lung aeration in patients with COPD: a high-resolution CT scan study. Chest 2010;138(2):305-314.

26. Lopes AJ, Nery FP, Sousa FC, Guimarães FS, Dias CM, Oliveira JF, Menezes SL. CPAP decreases lung hyperinflation in patients with stable COPD. Respir Care 2011;56(8):1164-1169.

27. Soares SM, Oliveira RA, Franca SA, Rezende SM, Dragosavac D, Kacmarek RM, Carvalho CR. Continuous positive airway pressure increases inspiratory capacity of COPD patients. Respirology 2008; 13(3):387-393.

28. Hoffman RA, Ershowsky P, Krieger BP. Determination of autoPEEP during spontaneous and controlled ventilation by monitoring changes in end-expiratory thoracic gas volume. Chest 1989;96(3): 613-616.

29. Massie CA, McArdle N, Hart RW, Schmidt-Nowara WW, Lankford A, Hudgel DW, et al. Comparison between automatic and fixed positive airway pressure therapy in the home. Am J Respir Crit Care Med 2003;167(1):20-23.

30. Lightowler JV, Wedzicha JA, Elliott MW, Ram FS. Non-invasive positive pressure ventilation to treat respiratory failure resulting from exacerbations of chronic obstructive pulmonary disease: Cochrane systematic review and meta-analysis. BMJ 2003;326(7382):185.

31. Dreher M, Storre JH, Schmoor C, Windisch W. High-intensity versus low-intensity non-invasive ventilation in patients with stable hypercapnic COPD: a randomised crossover trial. Thorax 2010;65(4): 303-308.

32. Tobin MJ. Respiratory muscles in disease. Clin Chest Med 1988; 9(2):263-286

33. Thurlbeck WM, Henderson JA, Fraser RG, Bates DV. Chronic obstructive lung disease. A comparison between clinical, roentgenologic, functional and morphologic criteria in chronic bronchitis, emphysema, asthma and bronchiectasis. Medicine 1970;49(2):81-146.

34. Engleman HM, Wild MR. Improving CPAP use by patients with the sleep apnoea/hypopnoea syndrome (SAHS). Sleep Med Rev 2003; 7(1):81-99.

35. Kribbs NB, Pack AI, Kline LR, Smith PL, Schwartz AR, Schubert $\mathrm{NM}$, et al. Objective measurement of patterns of nasal CPAP use by patients with obstructive sleep apnea. Am Rev Respir Dis 1993; 147(4):887-895. 